\section{Analysis of the iron profile and the incidence of iron deficiency anemia in the third-trimester pregnant women in the co- endemic areas of Bengkulu City, Indonesia}

\author{
Mohammad Zulkarnain, ${ }^{1}$ \\ Rizka Muliani, ${ }^{1}$ Rico Januar Sitorus, ${ }^{1}$ \\ Nurlaili $^{2}$
}

${ }^{1}$ Department of Epidemiology and Biostatistics, Faculty of Medicine, University of Sriwijaya; ${ }^{2}$ Department of Nursing, Faculty of Science, University of Bengkulu, Indonesia

\begin{abstract}
Pregnant women are at risk for iron deficiency anemia especially pregnant women in malaria-endemic areas. This study aimed to analyze the profile of iron in the third trimester pregnant women with iron deficiency anemia in co-endemic area of Bengkulu city. This study was cross-sectional study with a total sample of 66 pregnant women who met the inclusion criteria. Examination profile of iron in pregnant women is done by taking blood specimen through the vena cubity. Profile iron includes examination sTfR levels, hepcidin, transferrin were examined by ELISA. Determination of iron deficiency anemia is based on the results of $\mathrm{Hb}$, serum iron and TIBC. The results showed $39.4 \%$ of pregnant women experience iron deficiency anemia. There is an average difference between hepcidin levels with the incidence of iron deficiency anemia (p-value 0.031). Based on binary logistic regression analysis profile iron with irondeficiency anemia in pregnant women, hepcidin levels are predictors factors on the incidence of iron deficiency anemia ( $\mathrm{p}$-value 0.000, 95\% CI .296-.709).
\end{abstract}

\section{Introduction}

Iron is an essential micronutrient required for the process of erythropoiesis, oxidative metabolism and cellular immune responses, ${ }^{1}$ Iron deficiency and iron deficiency anemia in particular, remains one of the most severe nutritional deficiencies and important in the world today. Lack of iron impairs the cognitive development of children from infancy to adolescence. ${ }^{2,3}$

Anemia in pregnant women is a serious global health problem. According to the World Health Organization (WHO), approximately 32.4 million pregnant women suffer from anemia, of which 0.8 million women suffer severe anemia. In addition, the majority of cases of anemia due to iron deficiency anemia, ${ }^{4}$ Iron deficiency anemia arises when the balance of the intake of iron, iron storage, and loss of body iron is not enough to fully support the production of erythrocytes. For the diagnosis of iron deficiency anemia is not only based on the low levels of hemoglobin and serum iron is low, conversely an increase in Total Iron Binding Capacity. 5,6 To measure the availability of iron stores in iron transfer examination transferrin levels is to see and measure the maximum amount of iron that can be carried by the blood, ${ }^{7}$ Serum transferrin receptor level increases progressively as the supply of iron to the network becomes increasingly more deficient. The main advantage of measuring the serum transferrin receptor involves the fact that the test was not significantly affected by the infection or inflammation, 2,3 Hepcidin measurements performed to see the hormones involved in the control of iron homeostasis in the body. ${ }^{8}$

Pregnant women are more susceptible to iron deficiency anemia, due to the need for iron increases up to three times the amount required in all other populations, including men and women. The increase in the mass of red blood cells, and placental growth of the fetus, a major factor in pregnancies provide increased demand for more iron to maintain the normal growth of the fetus, ${ }^{9}$ Babies are directly affected by iron deficiency at birth and entering their first year of life. At this stage, the baby has a critical need for adequate nutrition to meet developmental milestones, both physically and cognitively. Babies born to mothers with iron deficiency anemia before giving birth even have the effect of physiological and cognitive development are worse compared with those born to mothers without iron-deficiency anemia. ${ }^{10}$

Anemia can also be caused by diseases such as malaria and worm infections. In pregnancy, the adverse effects of malaria infection are associated with increased maternal and fetal mortality, miscarriage, stillbirth, and premature birth. Malaria is currently one of the most disease, geographically widespread and deadly and is responsible for the deaths of approximately 600,000 people per year. ${ }^{11}$

According to data from 2013 Riskesdas anemia occurred in $37.1 \%$ of pregnant women in Indonesia, $36.4 \%$ of pregnant women in urban areas and $37.8 \%$ of pregnant women in rural areas. Bengkulu provincial health data in 2015 found iron deficiency anemia in pregnant women by
Correspondence: Rizka Muliani, Department of Epidemiology and Biostatistics Faculty of Public Health, University of Sriwijaya, Jl. Raya Palembang-Prabumulih Km. 32 Indralaya, OI, Sumatera Selatan 30662, Indonesia.

Tel.: +62.711.580169 - Fax: +62.711.580644 E-mail: rizkaagra08@gmail.com.

Key words: Iron Profile, Hepcidin, Anemia, Pregnancy, Iron Deficiency.

Acknowledgments: The authors would like to thank for the grant from competitive grants Sriwijaya University in 2018 and all relevant parties who have help in the preparation of the research.

Contributions: the authors contributed equally.

Conflict of interest: the authors declare no potential conflict of interest.

Funding: this study was supported by competitive grants Sriwijaya University in 2018.

Clinical trials: This study was conducted after approval from Health Research Ethics Committee of the Faculty of Public Health University of Sriwijaya.

Conference presentation: part of this paper was presented at the $3^{\text {rd }}$ International Symposium of Public Health, 2018 October 31 - November 1, Universitas Airlangga, Surabaya, Indonesia.

Dedication: the article is dedicated to Department of Epidemiology and Biostatistics Faculty of Public Health, University of Sriwijaya.

Received for publication: 28 July 2019.

Revision received: 9 September 2019.

Accepted for publication: 15 October 2019.

This work is licensed under a Creative Commons Attribution NonCommercial 4.0 License (CC BY-NC 4.0).

(C) Copyright: the Author(s), 2019

Licensee PAGEPress, Italy

Journal of Public Health in Africa 2019; 10(s1):1197 doi:10.4081/jphia.2019.1197

$45 \%$. Also according to the data of Ministry of Health, 2016 Annual Parasite numbers are still high Incidence Bengkulu city is $1.36 \%$. Research conducted in Bengkulu by Flora et al. and Manolov et al. shows the relationship between the profile of iron with iron deficiency anemia in pregnant women. ${ }^{12,13}$ From these data, it can be seen that a decline in the incidence of iron deficiency anemia in pregnant women, but the incidence of iron deficiency anemia is still 
quite high. One of the causes of iron deficiency anemia in pregnant women asides for malaria infection disease is also caused by hormonal changes in pregnant women, nutritional needs, as well as the availability of iron stores during pregnancy. Therefore it is necessary to conduct further research on the profile of iron with iron-deficiency anemia in the third trimester pregnant women co-endemic area of Bengkulu city.

\section{Materials and Methods}

This research is an analytic observational study using cross-sectional study design. The research location is in the city of Bengkulu, which is one malaria-endemic area. The population in this study are pregnant women have recorded in health centers of Bengkulu city. There were 66 samples chosen by purposive sampling method with inclusion criteria: $3^{\text {rd }}$ trimester pregnant mothers, and willing to participate in the study. Data collection was collected by interviewing pregnant women, to know the identity of the characteristics of pregnant women. examination anemia with Easy Touch, Slide Taking blood for malaria examination, taking a stool sample for examination worm, Taking venous blood for examination $\mathrm{Fe}$ and TIBC levels by spectrophotometric and for checking the levels of transferrin, sTfR, and hepcidin ELISA assay. After the data was collected and then it was analyzed by using univariate, bivariate, and multivariate analyzed. Univariate analysis will look at the incidence of iron deficiency anemia in pregnant women in the third trimester of the city of Bengkulu. Bivariate analysis was used to see the difference in average levels of the iron profile (transferrin, sTfR, and hepcidin). The bivariate analysis that was used was Independent T-test and Mann Whitney test with an alpha of $5 \%$. Multivariate analysis used a binary logistic regression to see the most dominant variables as predictors of incidence of iron deficiency anemia in third-trimester pregnant women.

\section{Results}

\section{Univariate analysis}

\section{Respondents characteristic research}

After the interviews and examination of the 66 third trimester pregnant women in seven health centers Bengkulu city, results are as follows. Based on Table 1. the $\mathrm{Hb}$ of pregnant women in the third-trimester with the highest Bengkulu city is not normal category by $58(87.9 \%)$. Fe content of thirdtrimester pregnant women with the highest Bengkulu city normal category of 35 (53\%). TIBC levels of third-trimester pregnant women with the highest Bengkulu city normal category by $36(54.5 \%)$.

Based Table 2, the frequency distribution of third trimester pregnant women age Bengkulu city with no risk category (21-34 years) by $56(84.8 \%)$. The frequency distribution of education third-trimester pregnant women Bengkulu city with low category (< high school) of $34(51.5 \%)$. The frequency distribution of malaria history thirdtrimester pregnant women with the highest Bengkulu city category does not exist (never infected) of $60(90.1 \%)$.

The average levels of transferrin in the third trimester pregnant women respondents was $48.34 \mathrm{ng} / \mathrm{mL}$, the average levels of Soluble Transferrin Receptor (sTfR) in the third trimester pregnant women respondents was $2.13 \mathrm{ng} / \mathrm{mL}$ and the average levels of hepcidin in the third trimester pregnant women respondents was $9.012 \mathrm{ng} / \mathrm{mL}$.

Frequency distribution of iron deficiency anemia, malaria and worm diseases in the third trimester of pregnant women in the co-endemic area of Bengkulu City

Based on Table 3, it can be seen that most pregnant women did not suffer from iron deficiency anemia $(61.6 \%)$. It also revealed that $100 \%$ pregnant women had

Table 1. Examination results $\mathrm{Hb}$, levels of $\mathrm{Fe}$ and TIBC levels in pregnancy.

\begin{tabular}{lcc} 
Variables & n & $\%$ \\
Hb & & \\
$<11 \mathrm{~g} / \mathrm{dL}$ & 58 & 87.9 \\
$\geq 11 \mathrm{~g} / \mathrm{dL}$ & 8 & 12.1 \\
Fe levels & & \\
$<37 \mathrm{ng} / \mathrm{mL}$ & 31 & 47 \\
$\geq 37 \mathrm{ng} / \mathrm{mL}$ & 35 & 53 \\
\hline $\mathrm{TIBC}$ levels & & \\
$\geq 385 \mathrm{ng} / \mathrm{m}$ & 30 & 45.5 \\
$<385 \mathrm{ng} / \mathrm{mL}$ & 36 & 54.5 \\
\hline
\end{tabular}

Table 2. Frequency distribution of age, education, and history of malaria in pregnancy.

\begin{tabular}{lccc} 
Variable & Measure results & Total & $\%$ \\
\multirow{2}{*}{ Age } & Risky $(\leq 20$ and $\geq 35)$ & 10 & 15.2 \\
\multirow{2}{*}{ Education } & Not Risky $(21-34$ yrs $)$ & 56 & 84.8 \\
& Low $(<$ high School $)$ & 34 & 51.5 \\
Malaria History & High $(\geq$ high School $)$ & 32 & 48.5 \\
& Yes & 6 & 9.9 \\
\hline
\end{tabular}

Table 3. Frequency Distribution of Iron Deficiency Anemia, Malaria and Worm Diseases In The Third Trimester of Pregnant Women In The Co-Endemic area of Bengkulu City.

$\begin{array}{lcc}\text { Variables } & \text { n } & \% \\ \text { Anemia Status } & & \\ \quad \text { Iron Deficiency Anemia } & 26 & 39.4 \\ \quad \text { No Iron Deficiency Anemia } & 40 & 61.6 \\ \text { Malaria } & 0 & 0 \\ \quad \text { Positive } & 66 & 100 \\ \quad \text { Negative } & & \\ \text { Worm Diseases } & 0 & 0 \\ \quad \text { Positive } & 66 & 100 \\ \quad \text { Negative } & & \end{array}$

Table 4. Differences mean levels and average transferrin hepcidin levels with iron deficiency anemia in third trimester of pregnant women in co-endemic area of Bengkulu City.

\begin{tabular}{llccccc} 
& Anemia status & Mean & Mann-Whitney U test & Wilcoxon W & Z Asymp. Sig. (2-tailed) \\
\multirow{2}{*}{ Transferrin levels } & Iron Deficiency Anemia & 47.1 & 518.5 & 1338.5 & -0.02 & 0.984 \\
& Not Iron Deficiency Anemia & 49.1 & & & \\
\multirow{2}{*}{ Hepcidin levels } & Iron Deficiency Anemia & 8.08 & 355.5 & 706.5 & -2.15 & 0.031 \\
& No Iron Deficiency Anemia & 9.61 & & & \\
\hline
\end{tabular}


negative malaria slide examination by malaria and worm infection distribution frequency of $100 \%$ negative using microscopic examination with eosin method.

\section{Bivariate analysis}

The difference in average levels profile substances with iron deficiency anemia in third trimester of pregnant women in coendemic area of Bengkulu City: transferrin and hepcidin levels

Based on Table 4, it shows the mean or average to each group. That group Iron Deficiency Anemia mean transferrin levels are $47.1 \mathrm{ng} / \mathrm{mL}$ lower than the average of the group photo that Iron Deficiency Anemia 49.1ng / $\mathrm{mL}$. In table shows the U value of 518.5 and the $W$ value of 1338.5 if converted to $\mathrm{Z}$ value then the magnitude of -0.02 . Sig value or $p$-value $>0.05$ is 0.984 then there is no significant difference between the mean levels of transferrin third-trimester pregnant women with iron deficiency anemia. There is a significant difference between the average levels of hepcidin on third trimester pregnant women with iron deficiency anemia.

\section{Levels of Soluble Transferrin Receptor (sTfR)}

Based on the Table 5 above the average levels of sTfR the third trimester of pregnant women with iron deficiency anemia was $2.136 \mathrm{ng} / \mathrm{mL}$ with a standard deviation $0.0746 \mathrm{ng} / \mathrm{mL}$, While the average level of sTfR the third trimester of pregnant women with iron deficiency anemia was $2.137 \mathrm{ng} /$ $\mathrm{mL}$ with a standard deviation of $0.0557 \mathrm{ng} /$ $\mathrm{mL}$. Statistical test result $\mathrm{p}$-value $=0,974$, mean at alpha $5 \%$ seen no significant differences average sTfR levels among pregnant women with iron deficiency anemia and pregnant women with iron deficiency anemia.

\section{Multivariate analysis}

\section{End of Logistic Regression Model}

It showed that hepcidin was the most influencing factors in reducing incidence of iron deficiency anemia with Exp B 0.494 (95\% CI 0.331 -0.738). High hepcidin levels in pregnant women have the possibility of protecting the incidence of iron deficiency anemia in the appeal of low hepcidin levels in pregnant women.

Models probability that can be built on the results of binary logistic regression multivariate analysis. The model can be seen from equation (1) to (4)

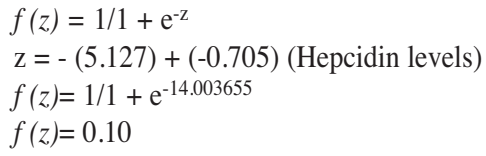

Probability Model with 5.708 hepcidin levels

$f(z)=1 / 1+\mathrm{e}^{-\mathrm{z}}$

$\mathrm{Z}=-(5.127)+(-0.705)$ (Hepcidin levels)

$f(z)=1 / 1+\mathrm{e}^{-9.15114}$

$f(z)=0.99$

Based on the results of the above, it can be concluded that pregnant women who have a hepcidin level of 5.708 have a probability of occurrence of iron deficiency anemia of $99 \%$. So the lower the level of hepcidin in pregnant women, the greater the chance for suffering from iron deficiency anemia.

\section{Discussion}

The bivariate test results between iron profiles (transferrin levels, sTfR levels, and hepcidin levels) showed that only the hepcidin level had an average difference with the incidence of iron deficiency anemia. In the group of Iron Deficiency Anemia the average hepcidin level was $8,089 \mathrm{ng} / \mathrm{mL}$ lower than the mean of the group No Iron Deficiency Anemia which was 9.612 ng / $\mathrm{mL}$. Hepcidin levels in the third-trimester pregnant women group but did not experience iron deficiency anemia had higher levels of hepcidin than third-trimester pregnant women with iron deficiency anemia (Table 6). The multivariate test results between iron profiles (transferrin levels, sTfR levels and hepcidin levels) showed that only the hepcidin level affected the incidence of iron deficiency anemia. This shows that there is a decrease in the level of hepcidin in the mother during pregnancy because the need for macro and micro nutrients has doubled to meet the needs of the mother and fetus during pregnancy. Hepcidin in pregnant women is lower than healthy women who are not pregnant and the level of hepcidin decreases during pregnancy, with the lowest level of hepcidin observed in the third trimester, 14 increasing the requirements of the fetus in the third trimester. for the observed decline in maternal hepcidin, demand for fetal iron in the third trimester of the largest. Signal that suppresses hepcidin mother during pregnancy is unknown. Specific regulator of hepcidin may be absent, or hepcidin can be suppressed in response to declining maternal iron levels during pregnancy. ${ }^{15}$

In the study conducted by Koenig et al. showed that serum hepcidin was significantly lower in pregnant women with Iron Deficiency Anemia and decreased hepcidin levels on the rise trimester of pregnancy compared with the control group with the lowest hepcidin levels observed in the third trimester. ${ }^{15}$ It is caused by increased iron needs of the fetus in the third trimester. Research is also conducted by Van Santen, et al shows the concentration of hepcidin decreases gradually from the first trimester and the second and third to undetectable levels $(\leq 0.5 \mathrm{nmol} / \mathrm{L})$ which was paralleled by a decrease in hemoglobin levels and iron parameter changes which indicate iron deficiency. ${ }^{16}$ During pregnancy hepcidin levels correlate with parameters of iron, but not with inflammatory markers. Research is also conducted by Schulze et al. showing that iron status is a major determinant of urine hepcidin concentration among pregnant women living in rural Bangladesh communities. Hepcidin tends to be a major regulator of iron metabolism during pregnancy, and this study provides strong evidence that iron status specifically affects hepcidin concentrations among Bangladeshi pregnant women. ${ }^{17}$

Iron is an essential micronutrient needed for erythropoiesis processes, oxidative metabolism and cellular immune responses. Iron is only needed by the body in small

Table 5. Differences in average levels of $s T f R$ with iron deficiency anemia pregnancy trimester III of Bengkulu.

\begin{tabular}{llccccc} 
& Anemia Status & Mean & SD & SE & p-value & n \\
\multirow{2}{*}{ sTfR levels } & Iron Deficiency Anemia & 2.136 & 0.0746 & 0.0146 & 0.974 & 26 \\
& No Iron Deficiency Anemia & 2.137 & 0.0557 & 0.0088 & & 40 \\
\hline
\end{tabular}

Table 6. The difference mean levels and average transferrin hepcidin levels with iron deficiency anemia in third trimester of pregnant women in co-endemic area of Bengkulu City.

\begin{tabular}{lccc} 
Variables & B & OR $(95 \%$ CI & p-value \\
Transferrin & 0.508 & $1,662(0.427-6.473)$ & 0.464 \\
sTfR & -0.791 & $0.453(0.119-1.723)$ & 0.246 \\
\hline Hepcidin & -0.705 & $0.494(0.331-0.738)$ & 0.001 \\
Constant & 5.127 & - & 0.001 \\
\hline
\end{tabular}


amounts. Therefore, a good regulatory mechanism is needed to regulate the absorption, distribution, and secretion of iron to maintain iron homeostasis. ${ }^{18}$ Iron deficiency will cause hematopoiesis and cellular metabolism, whereas iron overload can result in cell death due to free radical formation. ${ }^{19}$ Apart from being a regulator of iron levels in the blood, hepcidin is also known to play a role as an mediator of anemia in chronic diseases. ${ }^{20}$ Hepcidin appears to be a sensitive signal of iron deficiency compared with the hematocrit or hemoglobin, decreased levels of hepcidin is an early sign of iron deficiency along with changes in the value of reduced levels of transferrin saturation and ferritin. ${ }^{21}$

Hepcidin is a regulator of iron homeostasis and may be a useful biomarker for determining the bioavailability of iron in pregnancy, ${ }^{15}$ Prompt diagnosis of iron deficiency anemia and impaired circulation of iron in pregnancy may help doctors prescribe the right therapy with iron. ${ }^{22}$ Unfortunately, the value of hepcidin from human studies cannot be directly compared with each other because hepcidin tests have not been standardized, and different methods produce absolute values and normal ranges are different, although they are strongly correlated. An unknown amount of change in the value of hepcidin is biologically important during pregnancy. More research in larger populations are needed to determine the reference range for hepcidin during pregnancy. ${ }^{22}$ Pregnant women who have been indicated as anemic since before the pregnancy is predicted to experience iron deficiency anemia and low levels of hepcidin. Iron deficiency anemia may lead to the possibility of premature birth, low birth weight, fetal malnutrition what even maternal and infant mortality. Therefore it is necessary to do screening tests of anemia for teenager, women of childbearing age and pregnant women in early pregnancy to prevent early occurrence of iron deficiency anemia in pregnancy.

\section{Conclusions}

The profile of the most influential iron with iron-deficiency anemia in pregnant women is hepcidin levels. Hepcidin levels are predictors of occurrence factor deficiency anemia in third-trimester pregnant women. Examination of hepcidin levels can be used as a marker or predictor for assessing the probability of occurrence of iron deficiency anemia in pregnant women. It is recommended to implement early screening of anemia during pregnancy and in young women and women of childbearing age to prevent anemia and minimizing the occurrence of iron deficiency anemia.

\section{References}

1. Muñoz M, Villar I, García-erce JA. An update on iron physiology. World Journal of Gastroenterology 2009;15(37):4617-4626.

2. World Health Organization. Iron deficiency anemia: assessment, prevention and control. A guide for program managers. Geneva: World Health Organization; 2001.

3. World Health Organization. The Global Prevalence of Anemia in 2011. Geneva: World Health Organization; 2015.

4. Cook JD, Baynes RD, Skikne BS. Iron Deficiency and the Measurement of Iron Status. Nutrition Research Reviews 1992;5(1):198.

5. Guyatt GH, Oxman AD, Ali M, et al. Laboratory Diagnosis of Iron-deficiency Anemia: An Overview. J Gen Intern Med. 1992;7(2):145-53.

6. Yamanishi H, Iyama S, Yamaguchi Y, et al. The total iron-binding capacity calculated from serum transferrin concentration or serum iron concentration and unsaturated iron-binding capacity. Clinical Chemistry 2003;49(1):175178.

7. Elnabaheen EM, Zabout B, Alzaharna M. Hepcidin Status among Iron Deficient Anemic Pregnant Women in Gaza strip: A Case Control Study 2017. Available from: http://thesis.mandumah.com/Record/308402. Accessed on: 12 January 2018.

8. Krafft A, Murray-Kolb L, Milman N. Anemia and Iron Deficiency in Pregnancy. Journal of Pregnancy 2012;241869. Available from: https://doi.org/10.1155/2012/241869. Accessed on: 12 January 2018.

9. Cox AJ. The Effects of Iron Deficiency Anemia and Iron Supplementation in Pregnancy. Senior Honors Theses. 581. Available from: https://digitalcommons.liberty.edu/honors/581. Accessed on: 12 January 2018.
10. World Health Organization. World malaria report. Geneva: World Health Organization; 2013.

11. Flora R, Melvia B, Purwanto S. Profil Zat Besi Ibu Hamil di Daerah Endemis Malaria. Kesmas National Public Health Journal 2013;8(5):195-198.

12. Manolov V, Marinov B, Velizarova M, et al. Anemia in pregnancy and serum hepcidin levels. International Journal of Advanced Research 2015;3(1):758-761.

13. Gyarmati B, Szabó E, Szalay B, et al. Serum maternal hepcidin levels 3 days after delivery are higher compared to those measured at parturition. J Obstet Gynaecol Res. 2011;37(11):1620-4.

14. Koenig MD, Tussing-Humphreys L, Day J, et al. Hepcidin and iron homeostasis during pregnancy. Nutrients 2014;6(8):3062-83.

15. Van Santen S, Kroot JJ, Zijderveld G, et al. The iron regulatory hormone hepcidin is Decreased in pregnancy: a prospective longitudinal study. Clin. Chem. Lab. Med. 2013;51:1395.

16. Schulze KJ, Christian P, Ruczinski I, et al. Hepcidin and iron status among pregnant women in Bangladesh. Asia Pacific Journal of Clinical Nutrition 2008;17(3):451-456.

17. Siah CW, Ombiga J, Adams LA, et al. Normal iron metabolism and the pathophysiology of iron overload disorders. Clin Biochem Rev. 2006;27(1):5-16.

18. Munoz M, Garcia-erce JA, Remacha AF. Disorders of iron metabolism. Part 1: molecular basis of iron homeostasis. J Clin Pathol 2011;64:281-286.

19. Fleming RE, Bacon BR. Orchestration of Iron Homeostasis. New England Journal of Medicine 2005;352(17): 1741-1744.

20. Lasocki S, Longrois D, Montravers P, et al. Hepcidin and Anemia of the Critically Ill Patient: Bench to Bedside. Anesthesiology 2011;114(3):688-694

21. Weiss G, Goodnough LT. Anemia of chronic disease. N. Engl. J. Med. 2005;352: 101.

22. Kroot JJ, Hendriks JC, Laarakkers CM, et al. (Pre)analytical imprecision, between-subject variability, and daily variations in serum and urine hepcidin: Implications for clinical studies. Anal Biochem. 2009;389(2):124-9. 